\title{
Editorial
}

\section{THE HISTORY OF CZECH CLINICAL ANATOMY}

\author{
Josef Stingl*, Bruce O’Donnell, Vladimir Musil \\ Department of Anatomy, Third Faculty of Medicine, Charles University in Prague, Prague, \\ Czech Republic
}

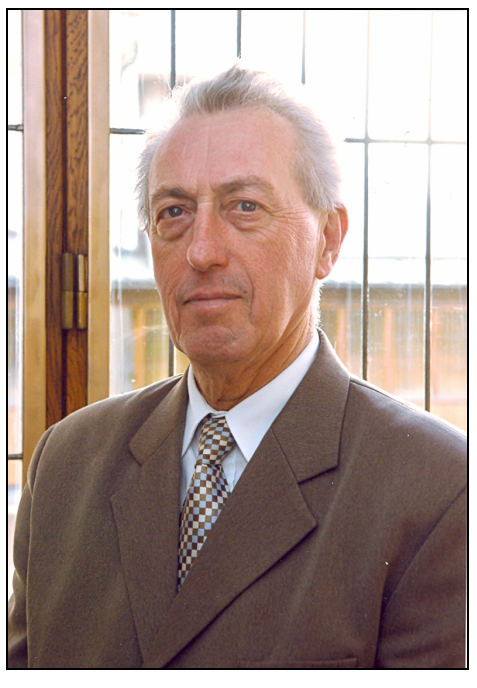

Prof. Josef Stingl

For more than 2000 years, medicine from the very beginning has placed anatomy as a cornerstone to its theoretical foundations. Throughout the centuries, most notably in the surgical disciplines, a fundamental knowledge regarding the orientation, description, arrangement and relationship of neighbouring organs and anatomical structures was an essential requirement. This was the birth of topographical anatomy (also known as regional, surgical, applied etc.). Today, this discipline is used in conjunction with many medical specialities, surgery in particular and has thus adopted the more appropriate title of 'clinical anatomy'. The Czech Republic (previously the Bohemian Kingdom and then Czechoslovak Republic from 1918-1992) is a small landlocked country situated in the heart of Central Europe. It is a country steeped in tradition, with a long and rich history in terms of its Universities, but in particular its medical curriculum. When discussing the historical development of clinically orientated human anatomy in the Czech Republic, there are several important periods of note:

\section{A. Origins $\left(14^{\text {th }}-16^{\text {th }}\right.$ century $)$}

The University in Prague was founded in 1348 by the Roman Emperor and King of Bohemia Charles IV as the $27^{\text {th }}$ oldest university in Europe. The University only initially contained the Faculties of Art, Law, Theology and Medicine. The quality of medical teaching at the time was reflected by the period and as such was rather limited. Anatomy was not considered a separate discipline, in fact a scholars first introduction to the structure and function of the human body, based on the principles of Aristotle, was during their bachelor studies at the Faculty of Art and was an obligatory requirement before they could begin their medical studies (Hyrtl, 1967).

This situation remained unchanged in the Bohemian Kingdom throughout the $15^{\text {th }}$ and $16^{\text {th }}$ centuries; however change was on the horizon with the dawn of a new century and period in Czech anatomical studies. In June 1600, Johannes Jessenius (1556-1621) (Fig. 1), a physician and professor of anatomy and surgery from Wittenberg in Saxony, performed the first public dissection in Prague. For five days, in front of over 1000 spectators, Jessenius dissected the body of a male criminal who had been hanged for

* Correspondence to: Prof. Josef Stingl, M.D., Ph.D., Department of Anatomy, Third Faculty of Medicine, Charles University in Prague, Ruska 87, 10000 Prague 10, Czech Republic. josef.stingl@lf3.cuni.cz 
his crime. One year later he published a 300 pages monograph (Fig. 2), titled Anatomiae Pragae (Jessenius, 1601), in which he described the dissection in detail. The text contained in this monograph clearly demonstrates that the biological principles of medicine at the time were ruled by the philosophy of Aristotle. Furthermore, the anatomical descriptions provided by Jessenius were almost identical to those contained in Vesalius' Fabrica (Vesalius, 1543) and did not as a result contain any new discoveries.

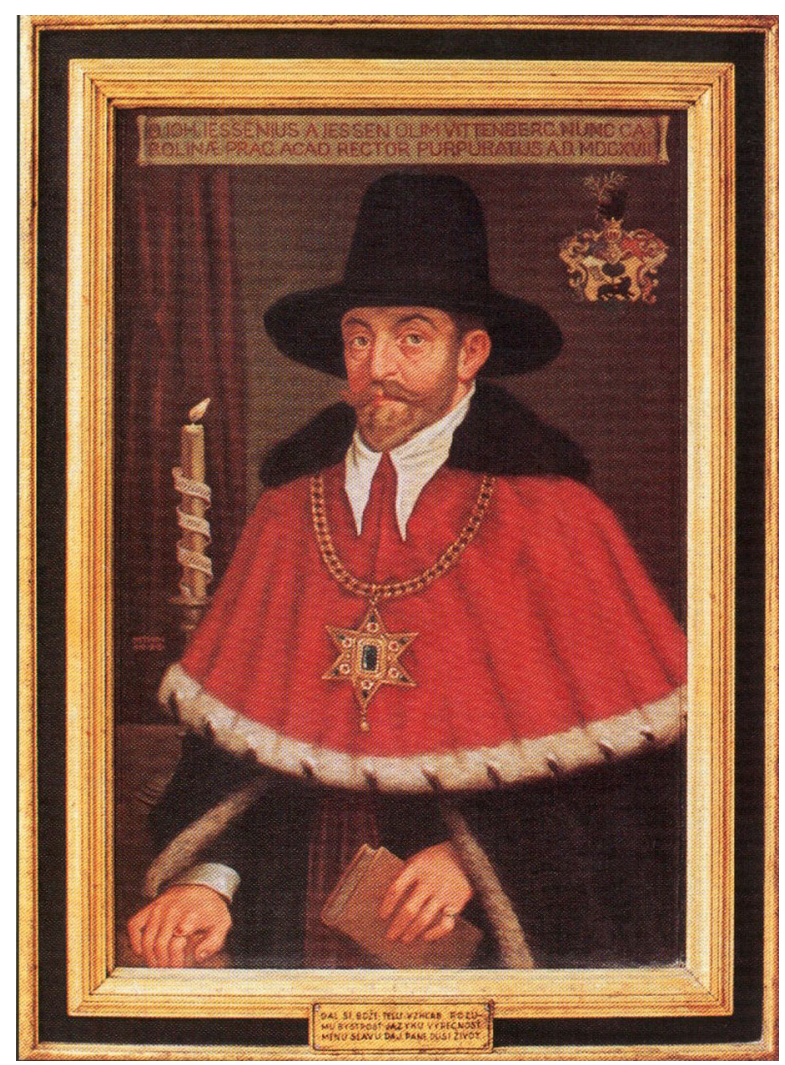

Figure 1: Portrait of Johannes Jessenius (1556-1621)

\section{B. Systematic development of dissection courses in anatomy $\left(17^{\text {th }}-18^{\text {th }}\right.$ century)}

Change came gradually in the medical curriculum, with occasional, albeit irregular dissections being performed from 1632 onwards. The arrival of professor Sebastian C. Zeidlern (1620-1689) however, saw a greater implementation of dissections into the teaching process as he established the first permanent dissection room in the Prague Monastery of the Merciful Brothers. In 1686 he published a textbook of anatomy, Somatotomia anthropologica seu corporis humani fabrica (Zeidlern, 1686), a first of its kind in the Bohemian Kingdom. All dissections at that time were performed by surgeons, under the supervision of the professor of anatomy.

The second half of the $18^{\text {th }}$ century marked the dawn of substantial changes, both in terms of health care and education, throughout the Austrian Empire, which included the Bohemian Kingdom. This was fuelled mainly by the intensive social and economic development occurring throughout Western Europe during this period. It was during the rule of Empress Maria Theresia and her son Emperor Josef II (17411790) that these reforms were implemented. Universities became state institutions and the decision was made to change the official teaching language from Latin to German.

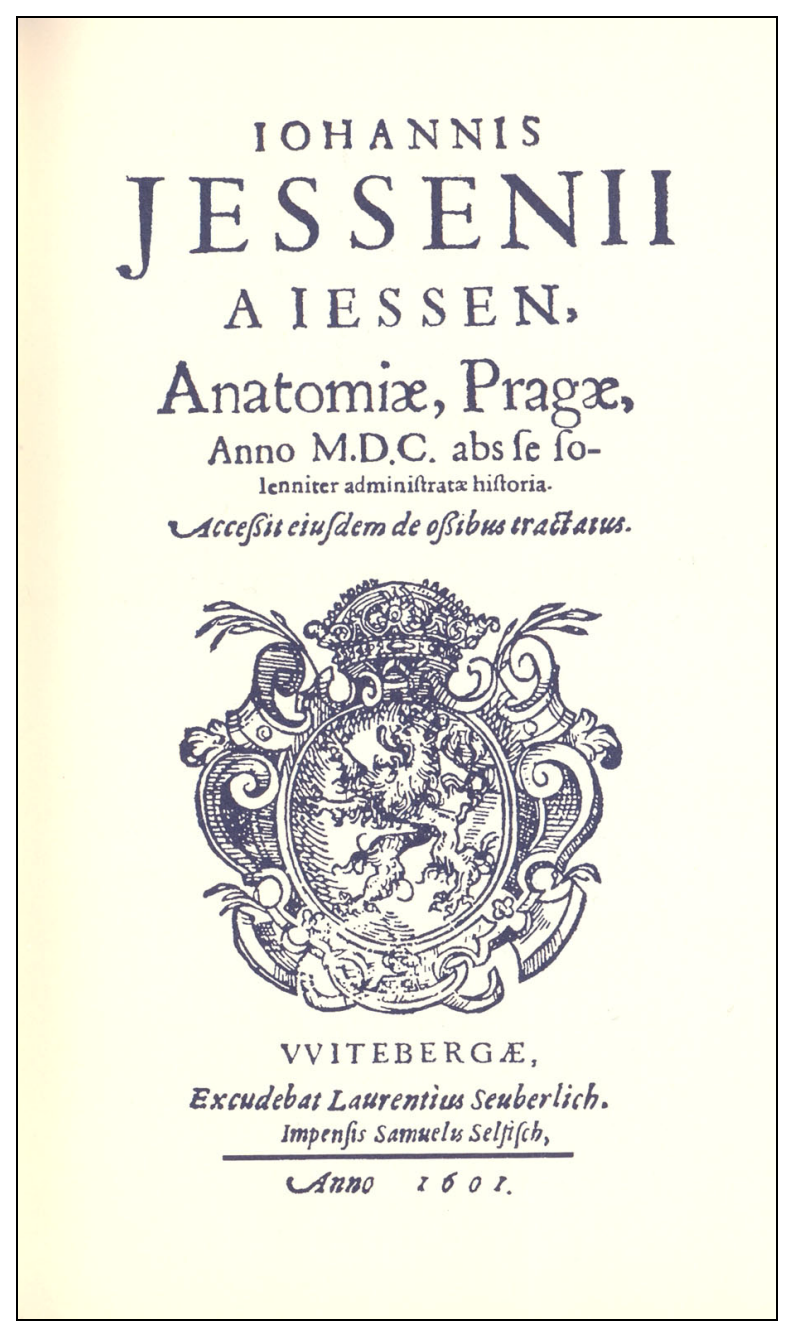

Figure 2: Cover page from the Jessenius' description of his Prague dissection (Jessenius, 1601) 
The contributions of the Bohemian Kingdom to the development and improvement of anatomy at the time can be attributed to two noteworthy anatomists:

Franciscus DuToy (1722-1784) graduated in Prague in year 1744 and substantially increased the collection of anatomical specimens at the Anatomy Department. He also introduced regular dissections as an essential teaching aid to the anatomical curriculum. He had a very keen and close relationship with surgery and was a firm advocate in the belief that anatomical knowledge was an essential part of this discipline.

Georg Prochaska (1749-1820), who studied in Vienna and was a professor of anatomy, physiology and ophthalmology in Prague (17781791) also made substantial contributions to improving the education of medical students by increasing the frequency of anatomical dissections performed. As an anatomist he became renowned for his use of contrast vascular injections, a skill which allowed him to be the first to describe the architecture of intramuscular blood vessels up to the capillary level. He received international recognition and was described by some as the father of reflex theory as a basic property in the nervous system. His textbook of physiology remained in use in Europe up to the 1830's.

\section{The era of descriptive anatomy $\left(19^{\text {th }}\right.$ century)}

Systemic and descriptive anatomy was an area of keen medical interest during this period. Technological advancements allowed the human body to be described not only on a macroscopic, but also a microscopic level. The latter half of the century saw the dynamic and substantial development of histology as a new frontier in medical understanding. This period also saw somewhat of a 'stagnation' in surgical disciplines and thus the intensive use of clinical anatomy was deemed unnecessary. Nonetheless, anatomists continued to make great strides in this field and the most notable individuals in Prague at the time were:

Georg Johann Ilg (1771-1836) assumed the post of a military surgeon after graduation and later became chairman of the Prague Anatomical Department, from 1809-1833. His contributions led to further development of the anatomical department, namely by substantially increasing its number of anatomical specimens.

Johann Evangelista Purkinje (1787-1869) studied medicine in Prague and after his graduation in 1818 , became prosector of the Department of Anatomy for a period of almost five years.
He then proceeded to become a professor of physiology in Breslau (Prussia) and remained there for many years. Although he was viewed negatively as an anatomist by his students, he later received worldwide notoriety among the medical community for his discoveries regarding the cellular construction of organisms, fibres of conducting system of the heart, cells of the cerebellar cortex and his discoveries on the physiology of the senses.

Joseph Hyrtl (1810-1894) was professor and chairman of the Prague Department of Anatomy in from 1837-1845. He later assumed the same position in Vienna from 1845-1874. He was author of several outstanding textbooks of systematic and topographical anatomy. As a researcher, he became famous and was regarded by some during the period as the 'master' of the vascular injection and corrosion cast technique.

Vincenz Bochdalek (1801-1883) who also graduated in Prague, became chairman of the Prague Department of anatomy from 1845-1871. Apart from anatomy, he was also an outstanding pathologist and to this day his discoveries regarding inborn defects of the diaphragm ("Bochdalek's herniae") are well known in paediatric surgery. During his chairmanship he implemented the foundation of a Course of surgical anatomy, instructed by the prosector Wenzel Gruber (1814-1890), who later (18471887) became chairman of the Department of Anatomy at the Military Medical Academy in St. Petersburg (Russia).

Another important and pivotal moment in the history of the University in Prague was its division into the German and Czech Charles University in 1883. The chairman of the German Anatomy Department, professor Carl Toldt (1840-1920) became an outstanding anatomist and embryologist. The Czech parallel was overseen by professor Vaclav Steffal (1841-1894). New complexes were constructed for each division and the Department of Anatomy was able to leave the cramped confines of the Karolinum, the historically recognised first building of the University that had housed the department for almost 500 years.

The final decades of the $19^{\text {th }}$ century was a period dominated by Professor Jan Janosik (1856-1927). Originally a pupil of Carl Toldt, he became a teacher of anatomy and upheld the finest traditions of descriptive anatomy. His research focused mainly on developmental anatomy and embryology and he was first to describe the existence of the pronephros in the human embryo in 1884. He also realised the importance of practically orientated anatomy and 
as such introduced a "Surgical anatomical course for doctors" into the anatomical curriculum in 1909.

\section{Systematical advancement of clinical anatomy (1900-1939)}

Czech clinical anatomy was to undergo its most notable transformation under the influences of professor Karel Weigner (1874-1937). Originally a pupil of Jan Janosik, he studied medicine in Prague and after his graduation became an anatomist. He devoted his entire career to furthering the development of practically orientated anatomy. In 1921 he became chairman of the 'Division of Topographical and Clinical Anatomy' of the Czech Anatomical Department. His work dealing with the projection of organs on the body surface was recognised throughout Europe. In the 1930's he published a five part textbook on topographical anatomy, in which he detailed his entire life's work as a clinical anatomist. He was promoted to Rector of Charles University in 1936 until his death in 1937. Under his influence, closer relationships were formed between anatomy and the other clinical specialities, particularly surgery. This led to and saw the emergence of many new surgical subcategories such as urology, traumatology, paediatric surgery, orthopaedics, neurosurgery, plastic surgery etc.

This period of advancement and discovery was tragically and violently disrupted by the occupation of the Czechoslovak Republic my Nazi Germany on March $15^{\text {th }}, 1939$. In defiance of the occupation, Czech students organised a protest that not only ended violently, but also with the closure of all Czech universities in Prague, Brno and Pribram. The universities remained closed until the end of the war in May 1945.

\section{E. The situation after 1945}

All Czech universities were reopened shortly after the end of the Second World War, which also saw the closure of the German parallel of Charles University. The post war atmosphere brought with it a renewed sense of hope and optimism and as a result three new medical faculties were established in Pilsen, Hradec Kralove and Olomouc. 1953 saw the division of the Medical Faculty in Prague into three independent institutions, bringing the total number of Medical Faculties within the Czechoslovak Republic to seven.

The post war scientific activities of Czech anatomy were, for several decades, orientated more so towards developmental and experim- ental morphology. The medical contribution of this research was not overly apparent. An exception to this case was professor Jan Hromada (1909-1970) at the Department of anatomy in Hradec Kralove, where he instructed a special course of surgical anatomy. The remaining medical faculties continued to teach classical topographical anatomy.

This was to change from the 1970's with such technological advancements as CT, MRI, endoscopic and laparoscopic procedures, invasive cardiology etc. The modern concepts of clinical anatomy began to take shape as there was a greater demand for cooperation between anatomists and the medical specialities on areas such as cross sections, variation anatomy and detailed topographical anatomy. One of the forefathers of this new collaboration in the Czechoslovak region was professor Milan Doskocil (1928-2002) from the Department of Anatomy at the First Faculty of Medicine of Charles University in Prague. Officially, clinical anatomy was defined as an integral, pedagogical and scientifically relevant aspect of the medical curriculum at the $34^{\text {th }}$ Congress of the Czech Anatomical Society (originally founded in 1953) in Olomouc in 1992.

Shortly after this declaration in 1993, the first as well as official collaborations between representatives of the Czech Anatomical Society and the leadership of the EACA (European Association of Clinical Anatomy) began. One of the greatest contributors to this cooperation, on the Czech side, can be contributed to the Third Faculty of Medicine of Charles University in Prague, particularly after 1999. One of its anatomists, Dr. Vaclav Baca, Assoc. Prof. to the Department of Anatomy, who successfully adopted the embalming methods set forth by Professor Walter Thiel (from Graz, Austria) and also founded the Educational Centre for Anatomy and Endoscopy in Prague, allowing for the instruction of numerous clinicians across a multitude of medical disciplines (Baca et al., 2006). To date more than 250 clinical colleagues have completed the course in clinical anatomy, allowing them the practical skills and training required to perform laparoscopic, pelvic, spinal and hip surgery as well as arthroscopy of the joints of the upper and lower extremities. Our department also fully endorses the systematic implementation of the official anatomical terminology set out by the Federative Committee on Anatomical Terminology (FCAT, 1998) in clinical practice (Kachlik et al. 2009).

As an expression of gratitude for our exceptional contributions and quality of work, we were asked to host the $9^{\text {th }}$ Congress of the EACA in 2007. 
This honour was also not without its historical merit, as while in session the 'International Academy of Clinical Anatomy' was officially established and the most important representatives in this discipline were identified.

Our department was further honoured when three of its anatomists were officially accepted as members of this organisation.

Over recent years we have also intensified our cooperation with colleagues from Southern Europe and the Middle East. We recently had the honour of organising and hosting the $2^{\text {nd }}$ Symposium of Clinical and Applied Anatomy, in which more than 120 clinical anatomists across the globe took part.

\section{REFERENCES}

Baca V, Doubkova A, Kachlik D, Stingl J, Svatos F. 2006. Possibilities of arthroscopy education in Educational Centre for Anatomy and
Endoscopy in Prague. Acta Chir Orthop trauma czech 73: 356-58.

Federative Committee for Anatomical Terminology. 1998. Terminologia Anatomica. Stuttgart: Thieme, 1-292.

Hyrtl J. 1967. Geschichte der Anatomie und ihrer Anstalt an der Carl-Ferdinands-Universität in Prag. Bad Reichenhall: Antiquar Rudolf Kleinert, 1-38.

Jessenius J. 1601. Anatomiae Pragae, Anno MDC abs se solenniter administratae historia. Wittebergae L. Seuberlich, 1-320.

Kachlik D, Bozdechova I, Cech P, Baca, Musil V. 2009. Mistakes in the usage of anatomical terminology in clinical practice. Biomed Pap Med Fac Univ Palacky Olomouc Czech Repub 153: 157-61.

Vesalius A. 1543. De humani corporis fabrica libri septem. Basileae: Ex officina loannis Opporini, 1-659.

Zeidlern SCh. 1686. Somatotomia anthropologica seu corporis humani fabrica. Pragae: Typis loannis Caroli Gerzabek, 1-160. 